\title{
Centrifuge modeling of suction bucket foundations for platforms under ice-sheet-induced cyclic lateral loadings
}

\author{
J.H. Zhang ${ }^{\mathrm{a}, *}$, L.M. Zhang ${ }^{\mathrm{b}}$, X.B. Lu ${ }^{\mathrm{c}}$ \\ ${ }^{a}$ State Key Laboratory of Hydroscience and Engineering, Department of Hydraulic Engineering, Tsinghua University, Beijing, 100084, China \\ ${ }^{\mathrm{b}}$ Department of Civil Engineering, The Hong Kong University of Science and Technology, Hong Kong, China \\ ${ }^{\mathrm{c}}$ Institute of Mechanics, China Academy of Science, Beijing, 100080, China
}

Received 4 April 2006; accepted 30 August 2006

Available online 1 November 2006

\begin{abstract}
This paper presents the results of a series of centrifuge model tests performed to study the behavior of suction bucket foundations for a tension leg platform in the Bohai Bay, China. The target lateral loadings were from ice-sheet-induced structural vibrations at a frequency of $0.8-1.0 \mathrm{~Hz}$. The results indicate that excess pore water pressures reach the highest values within a depth of $1.0-1.5 \mathrm{~m}$ below the mud line. The pore pressures and the induced settlement and lateral displacement increase with the amplitude of the cyclic loading. Two failure modes were observed: liquefaction in early excitations and settlement-induced problems after long-term excitations.
\end{abstract}

(C) 2006 Elsevier Ltd. All rights reserved.

Keywords: Suction bucket foundation; Laterally loaded pile; Dynamic loading; Centrifuge modeling; Liquefaction; Pore water pressure

\section{Introduction}

More than 50 platforms are to be built in the next 5 years for the exploitation of petroleum and natural gas in the Bohai Bay. Suction-installed foundations are one of the most promising types of foundation, since the industry demands reusable platforms offshore. The aspect ratio of suction buckets (i.e., ratio of height to diameter) used in practice in China is about 1.0. Fig. 1 shows the location of the Bohai Bay oil field and a typical suction foundation. As successful experience with the application of suction foundations in the Bohai Bay is still rather limited, design concepts of suction foundations for the conditions in the Bohai Bay need to be critically evaluated.

For nearly 3 months during the winter season, ice sheets form in the Bohai Bay and result in strong structural vibrations of the platform. The measured frequency of the structural vibrations is $0.8-1.0 \mathrm{~Hz}$. The ice-sheet-induced loading is featured by cyclic loadings of long durations. In order to investigate the dynamic response of the suction

\footnotetext{
*Corresponding author. Tel.: +8610 62792984; fax: + 861062785593.

E-mail addresses: cezhangjh@tsinghua.edu.cn (J.H. Zhang), cezhangl@ust.hk (L.M. Zhang), xblu@imech.ac.cn (X.B. Lu).
}

buckets and determine the minimum aspect ratio that satisfies design requirements, a series of centrifuge tests were performed in the 50-gt geotechnical centrifuge at Tsinghua University to assist the design of the foundations.

Physical models fill an important gap between full-scale filed observations and analytical solutions. The models should be large enough to provide reliable measurements and yet small enough to allow for a sufficient number of tests to be performed for design guidance (Rowe et al., 1978). Historically, laterally loaded piles were investigated in centrifuge (e.g., Mcvay et al., 1998; Zhang et al., 1999, 2002; Bang and Cho, 2002). Modeling suction piles by centrifuge testing has also been attempted by a number of researchers (Fuglsang and Steensen-Bach, 1991; Renzi et al., 1991; Clukey and Morrison, 1993, 1995; Waston and Randolph, 1997; Allersma et al., 1997, 1999; Cao, 2003; Zhang et al., 2003, 2005; Raines and Garnier, 2004; Kim et al., 2005). Dynamic loadings of a large number of cycles are encountered in the offshore environment. However, the dynamic response of suction foundations to long-duration structural vibrations has not been well understood.

This paper presents results of a series of centrifuge tests on suction bucket foundations under static and cyclic 

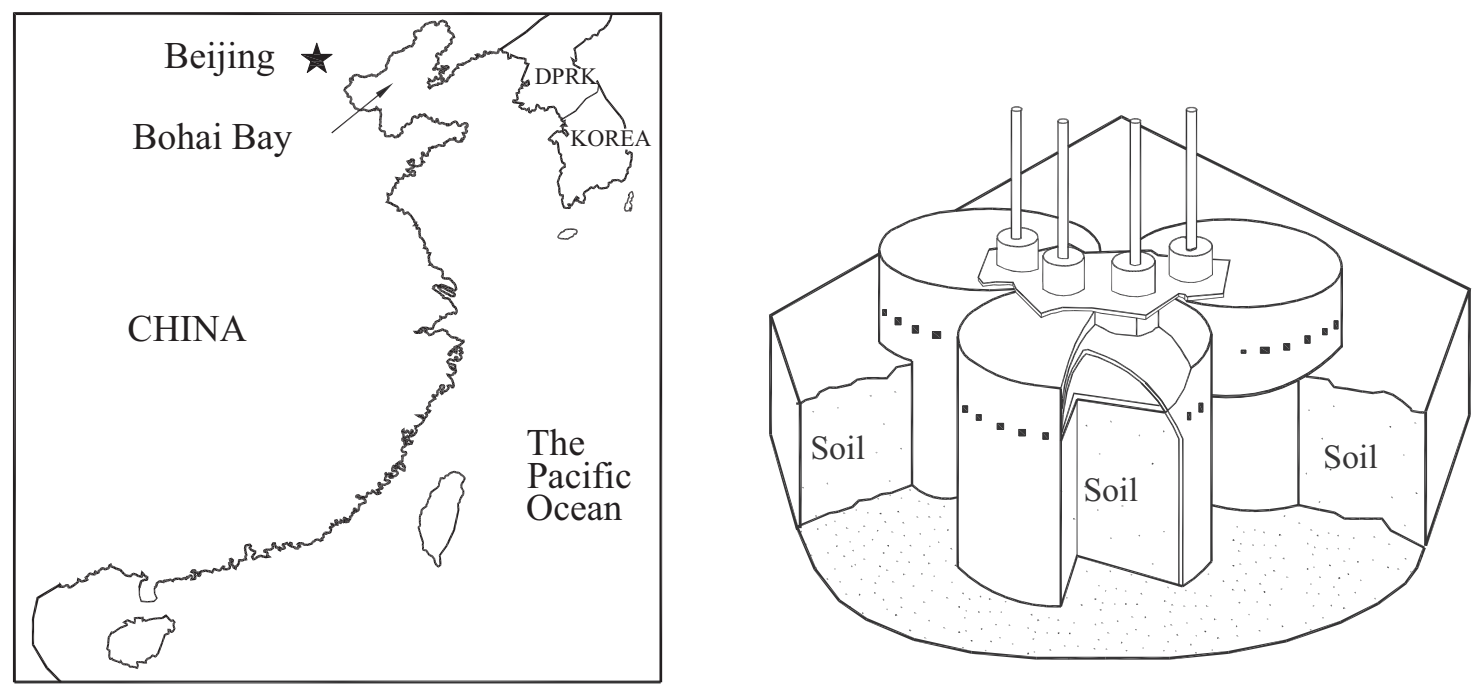

Fig. 1. Location of the Bohai Bay oil field and suction foundations.

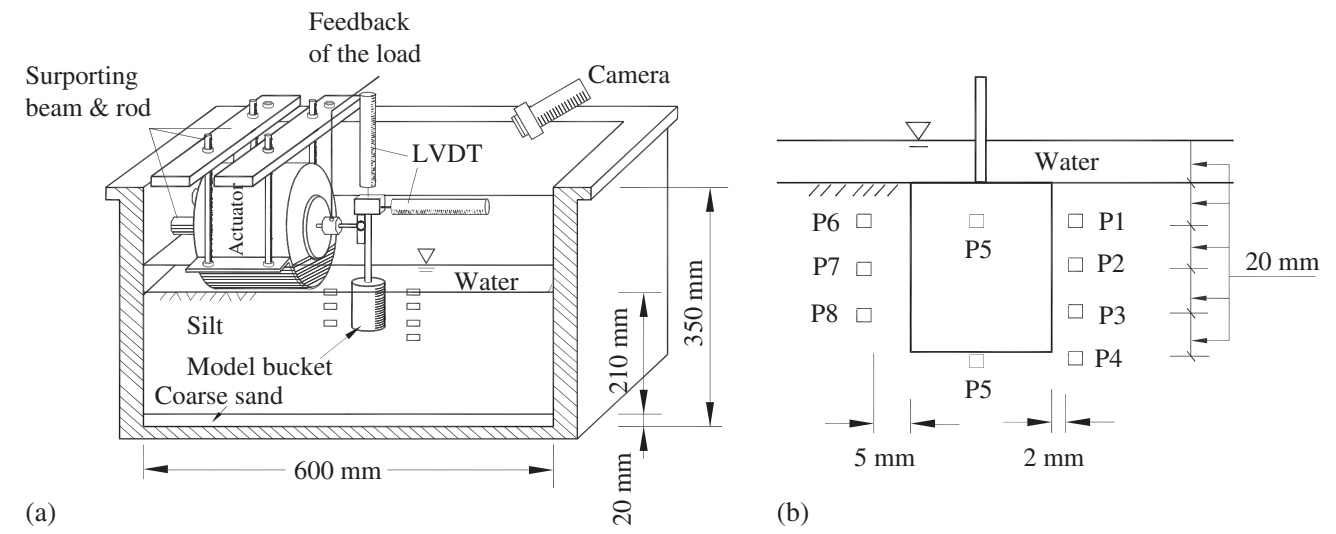

Fig. 2. Configurations of the centrifuge model (in model scale).

lateral loadings. The purpose of these tests was to study the characteristics of structural vibration-induced liquefaction of the soil in the vicinity of the suction bucket and investigate the influence of loading history and foundation geometry on the dynamic response of the foundation.

\section{Centrifuge model development}

\subsection{Model configuration}

The centrifuge model tests were carried out in the 50 -gt centrifuge at Tsinghua University (Pu et al., 1994). Fig. 2a shows the schematic diagram of the centrifuge model setup. The internal dimensions of the aluminum strong box are $600 \mathrm{~mm}$ in length and $350 \mathrm{~mm}$ in width and height. Two layers of soil were used: a $210-\mathrm{mm}$ thick silt at the top and a 20 -mm thick coarse sand at the bottom. The water level was $20 \mathrm{~mm}$ above the ground surface. The model bucket was a steel cylinder that had an outer diameter of $60 \mathrm{~mm}$ and a thickness of $1.5 \mathrm{~mm}$. Buckets of three different heights, 48, 72, and $90 \mathrm{~mm}$, were used; the corresponding aspect ratios were $0.8,1.2$, and 1.5 , respectively. A steel shaft $8 \mathrm{~mm}$ in diameter was attached to each bucket. The minimum depth from the foundation base to the bottom of the container was $120 \mathrm{~mm}$, which was twice the foundation diameter so that the boundary effects should be negligible (Prakasha et al., 2005). The dead weight of the platform was simulated by a ballast mounted on the top of the shaft. The centrifuge models were tested at $80 \mathrm{~g}$, so they would represent prototype bucket foundations $4.8 \mathrm{~m}$ in diameter. The movement of the bucket was monitored by two linear variable differential transformers (LVDTs). Nine pore pressure transducers (PPTs) were embedded in the silt to measure the pore-water pressure response. Fig. $2 \mathrm{~b}$ shows the layout of the PPTs in the model.

\subsection{Dynamic loading device}

The dynamic loading on the bucket foundation was applied through an electromagnetic actuator as shown in 
Fig. 3 (Zhang et al., 2003, 2005). This actuator consisted of a permanent magnet, a cylindrical silver coil, two copper disk springs, a load cell and a steel rod connected to the coil. The electromagnetic force drove the coil to move back and forth to apply cyclic loading on the model bucket through a rigid rod attached to the bucket. The actuator was $180 \mathrm{~mm}$ in diameter, $260 \mathrm{~mm}$ in length, and $14 \mathrm{~kg}$ in mass. The peak cyclic load was $100 \mathrm{~N}$ and the frequency range was $1-120 \mathrm{~Hz}$. The loading function was first generated from a computer signal generator and amplified through a servo amplifier. The latter in turn generated the necessary electrical signals to control the amplitude of electric current in the actuator. The input signal was a sinusoidal function, but the output signal captured by the load cell was irregular due to the complex system excited. The load output from the actuator was continuously measured by the load cell and fed back through a charged amplifier to the oscillograph. The actuator was supported
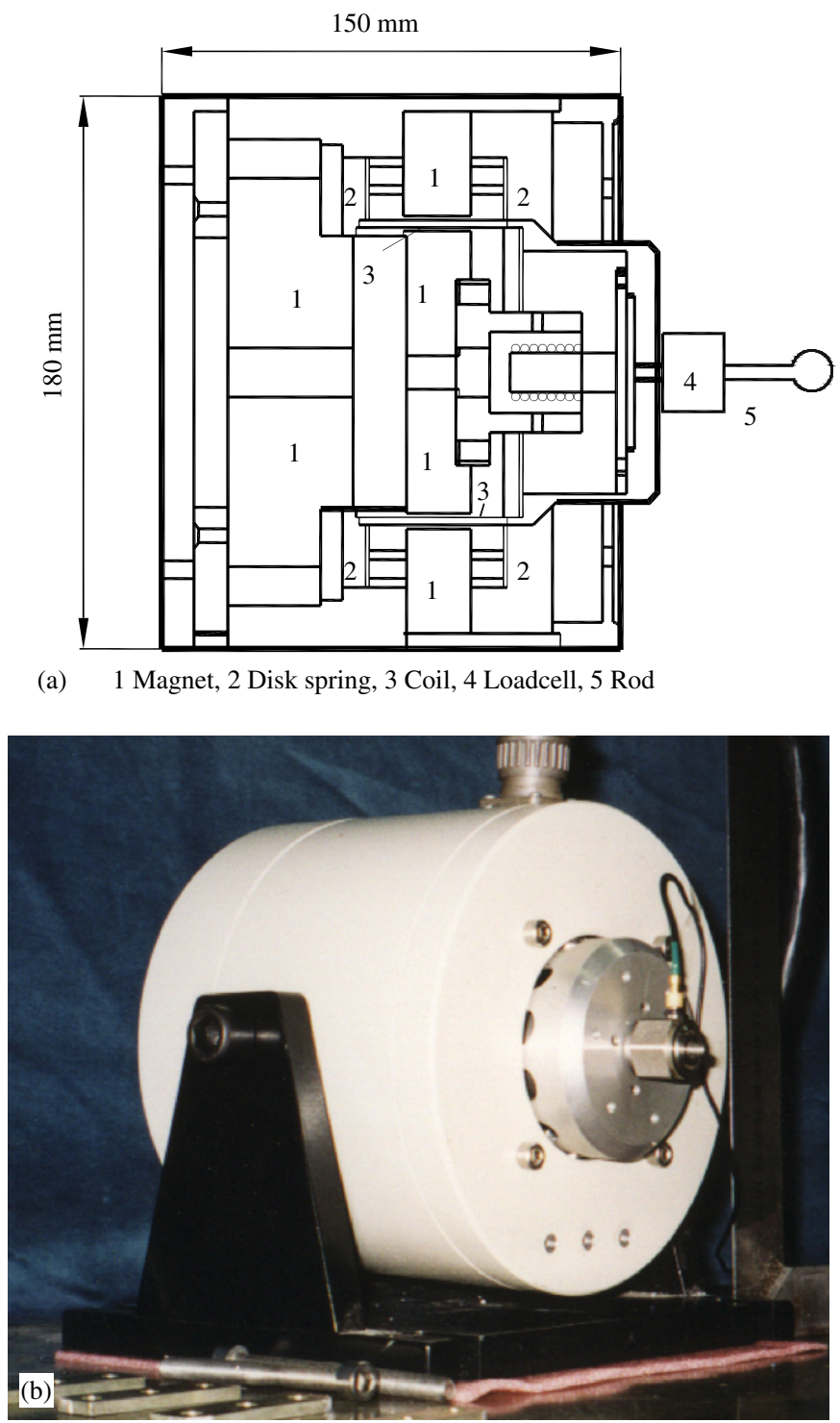

Fig. 3. The electromagnetic actuator.

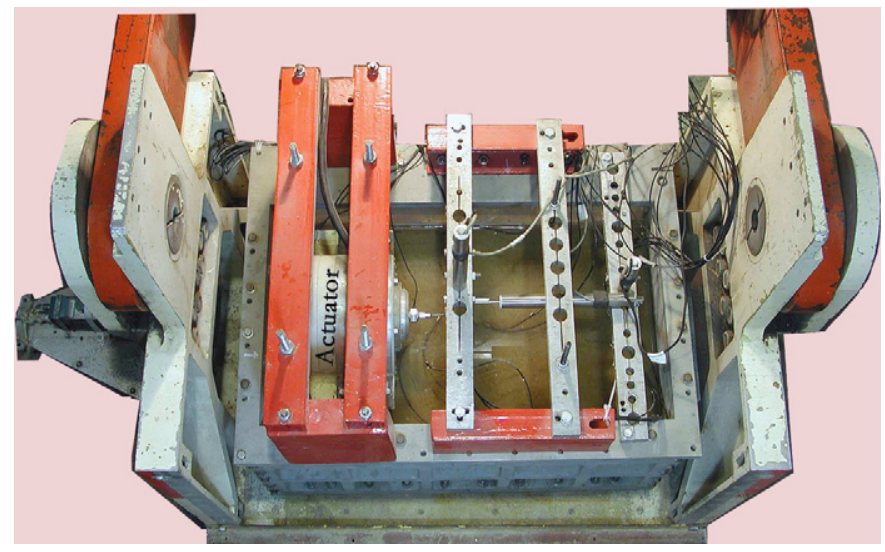

Fig. 4. The centrifuge model on the swing platform.

(see Fig. 2a) by two steel beams fastened on the flange. Two rods fixed the back of the actuator against the wall of the strong box, as shown in Fig. 2a. A miniature TV camera was attached to the flange of the model container to monitor the motion of the model bucket. Fig. 4 shows the centrifuge model package on the swing platform.

\subsection{Model soil preparation}

In dynamic centrifuge modeling, the inertial effect requires that the frequency and the amplitude of the lateral force be scaled by $N$ and $1 / N^{2}$, respectively, where $N$ is the geometric scale factor. The centrifuge tests were carried out with 1:80 scale models, e.g. the models were run at $80 \mathrm{~g}$. The frequency of the prototype cyclic loading was $0.8 \mathrm{~Hz}$, rendering a model frequency of $64 \mathrm{~Hz}$. Two approaches have been used to resolve the time-scale conflicts in dynamic centrifuge tests (Lee and Scholfield, 1988; Kutter and James, 1989). One is to use an artificial viscous pore fluid and the other is to use a soil with smaller coefficient of permeability. In this paper, a finer soil was used to reduce the permeability (Kutter and James, 1989). A silt which had a clay content of $3.2 \%$ was adopted so that water could still be used as the pore fluid. The reduction factor of the permeability was about 40 , less than 80 (the gravity scale factor). Therefore, the dissipation of pore water pressure in the models should be faster than that in the prototype, which might result in lower excess pore water pressures in the silty soil.

During the preparation of the centrifuge model, the soil was compacted in five lifts at a dry density of $1520 \mathrm{~kg} / \mathrm{m}^{3}$. Pore-water pressure transducers were embedded in the soil as shown in Fig. 2b. The steel model bucket foundation was installed at $1 \mathrm{~g}$. A hole on top of every model bucket was open when the model bucket was being installed. After installation, the hole was sealed. The model was saturated by a vacuum pump to degrees of saturation over $97 \%$. The soil model was consolidated at $80 \mathrm{~g}$. After consolidation, the dry density of soil was measured to be $1600 \mathrm{~kg} / \mathrm{m}^{3}$ and the effective unit weight was $784 \mathrm{kN} / \mathrm{m}^{3}$. The saturated 
Table 1

Properties of the test silt

\begin{tabular}{ll}
\hline Property & Value \\
\hline Specific gravity & 2.69 \\
Gradation & \\
$0.074 \mathrm{~mm}<d<0.5 \mathrm{~mm}$ & $81.5 \%$ \\
$0.005 \mathrm{~mm}<d<0.074 \mathrm{~mm}$ & $15.3 \%$ \\
$d<0.005 \mathrm{~mm}$ & $3.2 \%$ \\
Grain size & \\
$D_{60}(\mathrm{~mm})$ & 0.15 \\
$D_{10}(\mathrm{~mm})$ & 0.035 \\
Uniformity coefficient & 4.28 \\
Coefficient of permeability $(\mathrm{m} / \mathrm{s})$ & $2 \times 10^{-6}$ \\
Shear strength parameters & \\
Cohesion (kPa) & 0 \\
Effective friction angle (deg) & 35.0 \\
\hline
\end{tabular}

permeability at this dry density was measured to be $2 \times 10^{-6} \mathrm{~m} / \mathrm{s}$. Triaxial compression tests were performed to obtain the consolidated drained shear strength parameters. The effective cohesion and effective internal friction angle are $c^{\prime}=0$ and $\phi^{\prime}=35^{\circ}$, respectively. The properties of the soil are listed in Table 1.

\section{Test procedure and program}

The model was moved onto the platform of the centrifuge after the saturation of the soil. The soil was consolidated under $80 \mathrm{~g}$ for 6 months in prototype scale. The consolidation settlement recorded by a LVDT was $800 \mathrm{~mm}$. After that, the bucket foundation was subjected to a static lateral load test or a lateral cyclic load test. The static vertical load on the bucket, $2048 \mathrm{kN}$ in prototype scale, was simulated by the weight of the model bucket plus a mass attached to the shaft. The model test program is shown in Table 2. Two static lateral load tests were first performed, in which the models were loaded monotonically. These two tests were aimed at finding the staticbearing capacity as well as checking the repeatability of the centrifuge tests. Five cyclic model tests were performed afterwards to evaluate the effects of load intensity and aspect ratio on the behavior of the bucket foundation under horizontal cyclic loading. The cyclic loading period for each of the five model tests was approximately $20 \mathrm{~min}$ at $64 \mathrm{~Hz}$ in model scale, corresponding to $26.7 \mathrm{~h}$ at $0.8 \mathrm{~Hz}$ in prototype scale. The electromagnetic actuator was loadcontrolled. The output signals from the load cells, PPTs and LVDTs were first converted to digital data and then passed across the centrifuge slipring into a data acquisition system in a computer. During excitation, the shape of the load function remained unchanged. The magnitude of the load might decrease but not significantly.

In the following sections, the test results are presented in prototype scale to facilitate applications.
Table 2

Test program for Models 1-7

\begin{tabular}{llllll}
\hline Test no. & $\begin{array}{l}\text { Diameter } \\
(\mathrm{m})\end{array}$ & $\begin{array}{l}\text { Height } \\
(\mathrm{m})\end{array}$ & $\begin{array}{l}\text { Aspect } \\
\text { ratio } \\
\text { (height/ } \\
\text { diameter })\end{array}$ & $\begin{array}{l}\text { Static } \\
\text { load } \\
(\mathrm{kN})\end{array}$ & $\begin{array}{l}\text { Cyclic } \\
\text { load } \\
(\mathrm{kN})\end{array}$ \\
\hline 1 & 4.8 & 5.76 & 1.2 & $0-658$ & - \\
2 & 4.8 & 5.76 & 1.2 & $0-658$ & - \\
3 & 4.8 & 5.76 & 1.2 & - & 128 \\
4 & 4.8 & 5.76 & 1.2 & - & 256 \\
5 & 4.8 & 5.76 & 1.2 & - & 384 \\
6 & 4.8 & 7.20 & 1.5 & - & 256 \\
7 & 4.8 & 3.84 & 0.8 & - & 256 \\
\hline
\end{tabular}

\section{Static model test results}

Results of the static load tests on Models 1 and 2 are shown in Fig. 5. The model bucket foundation was monotonically loaded to large lateral displacement. Fig. 5a shows the relationships between the lateral loading, $H$, and the displacements, $X$, at the top of the model bucket foundation. The curves are relatively linear at the beginning but exhibit strong nonlinearity after a certain load is exceeded. The lateral load is also plotted against the rotation angle of the bucket in Fig. 5b. As seen in Figs. 5a and $b$, the load-displacement relationships for both tests were similar, implying that the tests were repeatable. Under the lateral load, the bucket rotated about a point on the vertical centerline of the bucket. The rotation point could be found by a linear extrapolation of the displacement at two points measured by the LVDTs. Fig. 6 depicts the estimated depths of the rotation point. At the beginning of the loading, the rotation point is located very shallow and remains unchanged until the load exceeds about $260 \mathrm{kN}$, indicating a very stiff state of the soil. It was consistent with the linear curve part in Fig. 5a, in which the horizontal load increases linearly with the horizontal displacement. Afterwards, the rotation point moves downward and the load-displacement curves tend to be flatter.

In order to find the static bearing capacity, the horizontal load, $H$, is plotted against the displacement rate as shown in Fig. 7, in which the displacement rate is defined as the ratio of the displacement increment to the load increment. In Fig. 7, the test data can be fitted with a trilinear curve with two intersection points. The first intersection point denotes the critical bearing capacity of $327 \mathrm{kN}$, whereas the second intersection point denotes the ultimate bearing capacity of $513 \mathrm{kN}$. The static bearing capacity is used to determine the cyclic load in the subsequent dynamic centrifuge tests. The model bucket after test is shown in Fig. 8. A large tilting of about 15 degrees occurred.

\section{Dynamic response to cyclic loads of different magnitudes}

In this series of tests, three cyclic loading tests with peak loads of 128,256 , and $384 \mathrm{kN}$ were conducted to 

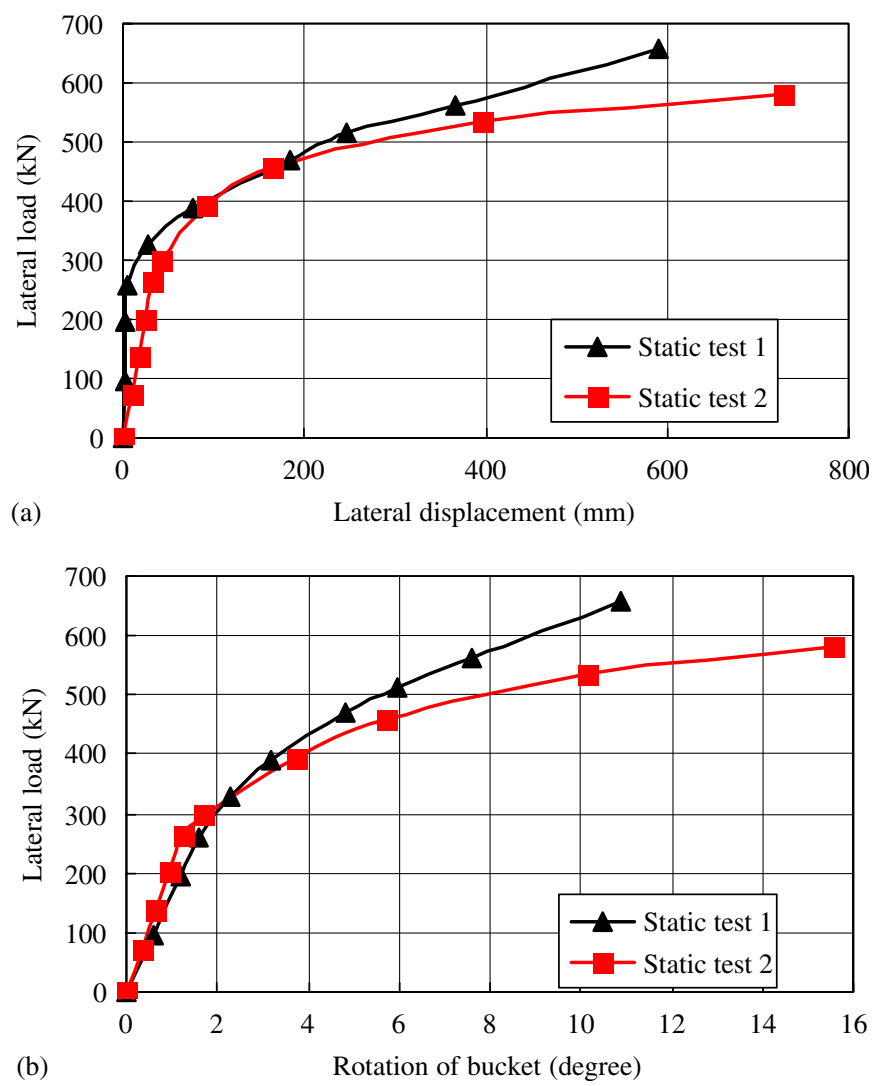

Fig. 5. Relationships between horizontal load and horizontal displacement and rotation of the bucket foundation.

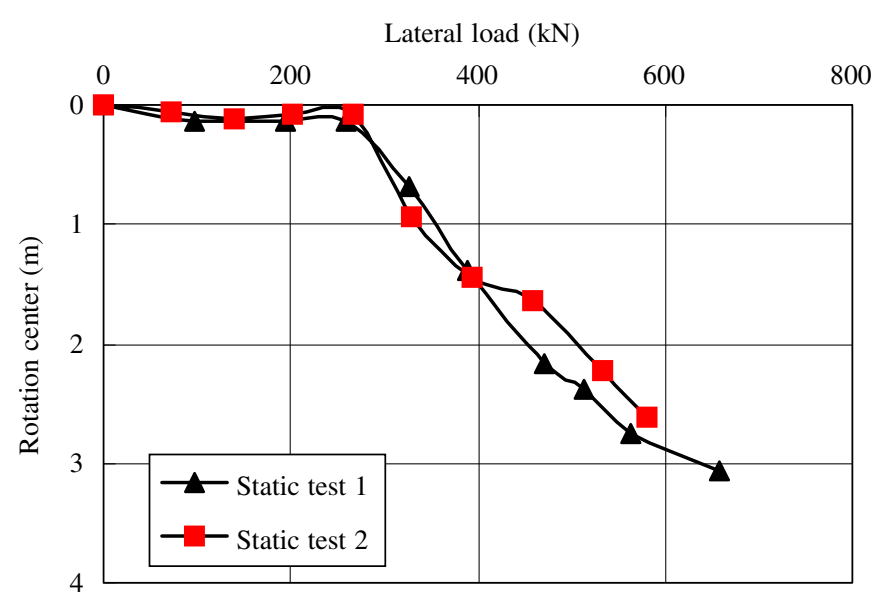

Fig. 6. Depth of rotation point of the bucket foundation.

investigate the dynamic response of the bucket foundation to different load intensities. The highest peak load was slightly greater than the static critical capacity $327 \mathrm{kN}$, or about $70 \%$ of the static ultimate capacity $513 \mathrm{kN}$, which was revealed by the static load tests described in the previous section. The two lateral loads, 128 and $256 \mathrm{kN}$, were $1 / 3$ and $2 / 3$ of the largest test load $384 \mathrm{kN}$. Measured pore water pressure responses in the soil and vertical and lateral movements of the bucket foundations are presented in this section. The layout of the PPTs before the centrifuge

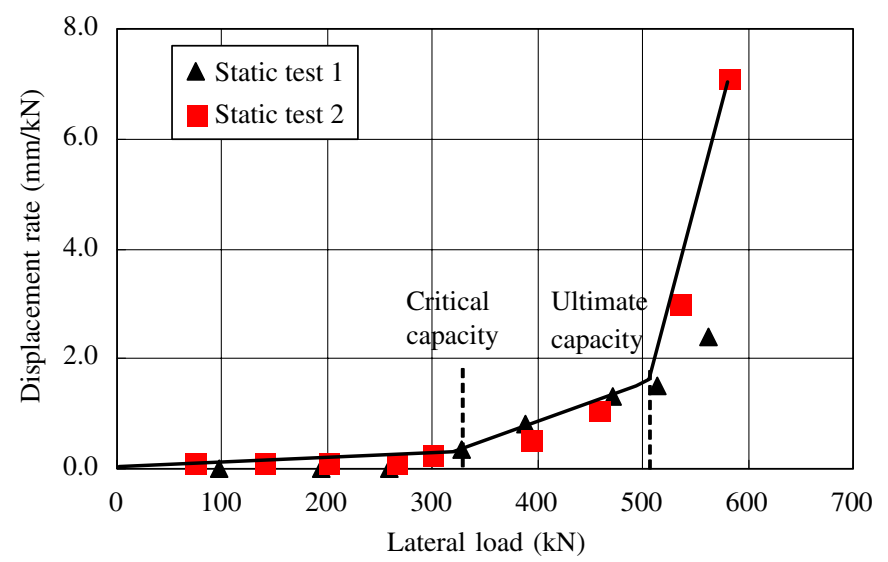

Fig. 7. Static bearing capacity of the bucket foundation.

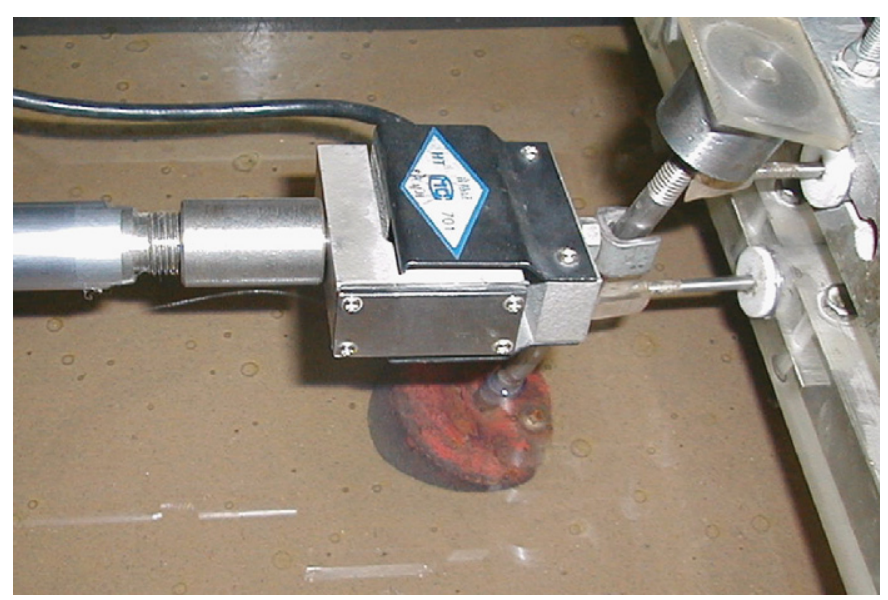

Fig. 8. The centrifuge model after test.

tests is shown in Fig. 2b. The final locations of the PPTs were identified after the test, since the transducers might move during the soil consolidation and the cyclic loading test. For Model 3, transducer P5 was placed underneath the bucket, while for Models 4 and 5, P5 was placed inside the bucket and the pore pressure depended on the soil response within the bucket.

Fig. 9 depicts the applied cyclic loading histories and Fig. 10 presents measured pore-water pressures at four locations (i.e., P1-4) for the three dynamic tests on a bucket foundation with an aspect ratio of 1.2. The amplitudes of cyclic loading are 128,256 , and $384 \mathrm{kN}$, respectively. The loading functions are approximately sinusoidal.

Fig. 10 shows excess pore pressures built up in all three models; however, the dynamic responses are different associated with each load intensity. The amplitude of the cyclic load on Model 3,128 kN, is the lowest; the generated pore pressures (see Fig. 10) are hence the lowest. Under this low level of excitation, a soil compaction mechanism dominates, resulting in steadily increased pore pressures in about $10 \mathrm{~h}$. The pore pressures at P1 with at a depth of $1.5 \mathrm{~m}$ are the largest. Below P1, the pore pressures decrease with the depth. Due to the partial drained condition, the 

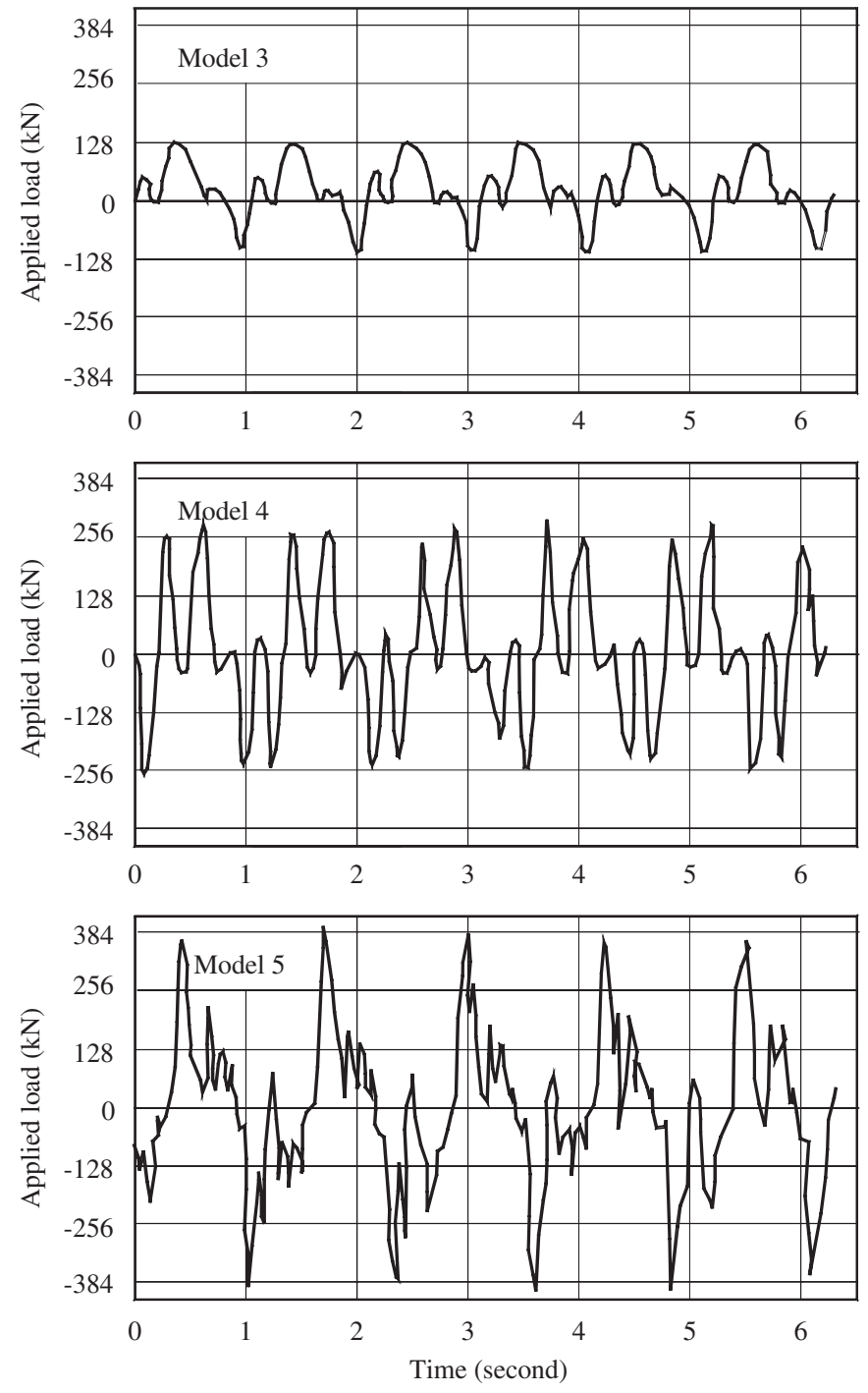

Fig. 9. Applied loading histories in Models 3-5.

build-up and dissipation of pore pressure occur simultaneously, so the residual pore pressures remain almost constant in the subsequent excitations. The liquefaction potential should be rather low since the ratio of the pore pressure $\Delta u$ to the initial free-field vertical effective stress $\sigma_{\mathrm{v}}^{\prime}$, e.g. $\Delta u / \sigma_{\mathrm{v}}^{\prime}$, at most depths is less than 0.27 .

When the cyclic load is greater than half of the critical static capacity, i.e., $256 \mathrm{kN}$ in Model 4 shown in Fig. 10b, soil-compaction-induced pore pressures are much higher within a depth of $1.5 \mathrm{~m}$ due to the stronger excitation. At the beginning of the excitation, the pore pressures especially at a depth of $1.5 \mathrm{~m}$ increases rapidly to a very high value in $3 \mathrm{~h}$, and then drops with further excitation. The drop is thought to be the result of soil dilation and development of negative pore pressures at shallow depths (Li, 2002). Due to the partial drained condition, the pore pressures sustain during further excitation. The maximum pore pressure is 0.74 times the initial free-field vertical effective stress at the corresponding position in Model 4.
Furthermore, the cyclic load in Model 5, $384 \mathrm{kN}$, is the highest and greater than the critical static capacity. The maximum pore pressure is accordingly the highest among the three models, resulting in a high liquefaction potential. As seen in Fig. 10c, at the beginning of the excitation, the pore pressure at a depth of $1.5 \mathrm{~m}$ (at P1) in Model 5 increases rapidly to a very high value in about $1 \mathrm{~h}$; the maximum pore pressure is about three times that in the counterpart point in Model 3. In this case, the maximum pore pressure in Model 5 rises much more quickly than that in Model 4 due to higher load intensity. The maximum $\Delta u / \sigma_{\mathrm{v}}^{\prime}$ ratio is 0.96 in Model 5, indicating much higher potential of liquefaction. Nevertheless, after the maximum pore pressure has developed, significant soil dilation occurs, leading to abrupt drop of the pore pressures. After the maximum values, the pore pressures keep constant due to the simultaneous occurrence of the build-up and dissipation of pore pressure. It is seen in Fig. 10, the pore pressures in Model 5 are the highest values at the corresponding time among the three models, which is correlated with the load intensities.

Fig. 11 compares the dynamic responses in Models 3-5. Fig. 11a shows the changes in the maximum pore pressure with depth in the three models. For all three models, the pore pressure reaches the highest value at a depth of about $1.5 \mathrm{~m}$ below the mud line and then drops with the depth. The pore pressure profiles are well related to the load intensity. The dynamic response of the foundation can be more clearly demonstrated by the $\Delta u / \sigma_{\mathrm{v}}^{\prime}$ values in Fig. $11 \mathrm{~b}$. The $\Delta u / \sigma_{\mathrm{v}}^{\prime}$ values at P1 for Models $3-5$ are $0.27,0.74$, and 0.96 , respectively, and the $\Delta u / \sigma_{\mathrm{v}}^{\prime}$ values tend to decrease sharply at large depths. Consequently, liquefaction is not likely when the horizontal load intensity is $128 \mathrm{kN}$, but may occur when the load intensity is increased to $384 \mathrm{kN}$.

Owing to the long duration of excitation, soil softening induced significant horizontal and vertical displacements of the foundation. Fig. 12 shows the lateral and vertical displacements of the foundations in Models 3-5. The permanent displacements are in accordance with the load intensity. The permanent lateral displacements are 8.7, 40, and $84 \mathrm{~mm}$, and the permanent vertical displacements are 173, 574, and $768 \mathrm{~mm}$ for Models 3-5, respectively. Although the peak cyclic loads on Models 3-5 are proportional at 1.0:2.0:3.0, the proportions of the horizontal displacement and settlement of the foundations are 1.0:4.6:9.7, and 1.0:3.3:4.4, respectively. Owing to the longduration excitations, the soil in the vicinity of the bucket foundation became very dense after the tests.

In the three tests, the load intensity had a strong effect on the dynamic behavior of the foundation. However, although the load duration was $26.7 \mathrm{~h}$, the period liquefaction was likely to occur was within the first $1-3 \mathrm{~h}$. The greater the intensity of the load, the earlier liquefaction could occur. During the excitation, soil-softening-induced horizontal displacements and vertical settlements were significant, especially for the load of the greatest intensity. As a result, it can be inferred that two failure modes may 

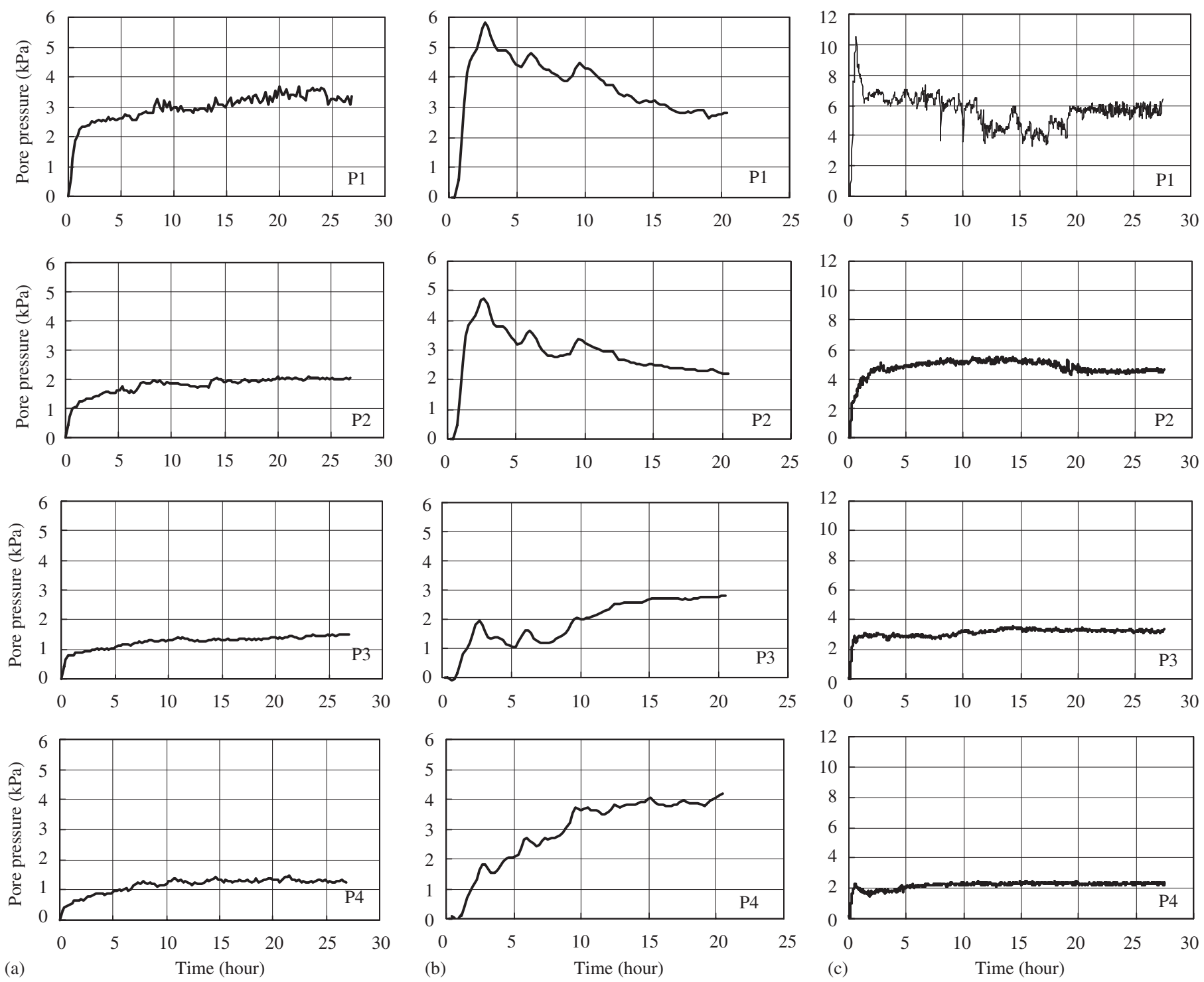

Fig. 10. Pore-water pressure changes.

be involved: liquefaction in early excitations and displacement-induced problems after long-term excitations.

\section{Dynamic response of models with different aspect ratios}

In this section, results of Models 6, 4, and 7 with different aspect ratios of $0.8,1.2$ and 1.5 are presented to investigate the effect of aspect ratio on the dynamic response of the suction foundations. The intensities of cyclic load in these models were all $256 \mathrm{kN}$. As revealed in the above section, the maximum $\Delta u / \sigma_{\mathrm{v}}^{\prime}$ ratio was 0.74 in Model 4 with an aspect ratio of 1.2. The applied cyclic load should be a strong excitation for the model with an aspect ratio of 0.8 but not very strong for the model with an aspect ratio of 1.5 , since the capacity depends on the embedment depth of the foundation.

Fig. 13 shows the histories of the applied lateral cyclic loads. The shapes of the load functions only differ slightly. Fig. 14 presents the pore-water pressures measured at P1-4 in the three models. Because of the shorter height of Model 6, P4 was located underneath the model bucket. As seen in Fig. 14, the dynamic responses of the two models with aspect ratios of 1.2 and 1.5 are similar. The pore pressures build up rapidly to a peak value due to the cyclic load within $1-3 \mathrm{~h}$, then the successive excitations result in soil dilation and the pore pressures decrease. However, for Model 6 with an aspect ratio of 0.8 , the dynamic response is significantly stronger. The excess pore pressures are mostly the highest among the three models owing to its lowest aspect ratio.

Fig. 15 compares the dynamic responses of Models 6, 4, and 7. Fig. 15a shows the profiles of pore pressure in the three models. The response within a depth of $1.5 \mathrm{~m}$ is significant as indicated before. For Model 6 with the smallest aspect ratio of 0.8 , there are some fluctuations, e.g., the pore pressure increases towards the base of the bucket. Model 4 (with an aspect ratio of 1.2) also exhibit the similar phenomenon, as shown in Fig. 11a, although 
not as significant as in Model 6. It is considered that, when the bucket rotated, the soil movements near the rotation point were relatively small, resulting in relatively insignificant pore-water pressure response. For Model 7 with an aspect ratio of 1.5 , there is no such fluctuation of pore

(a)
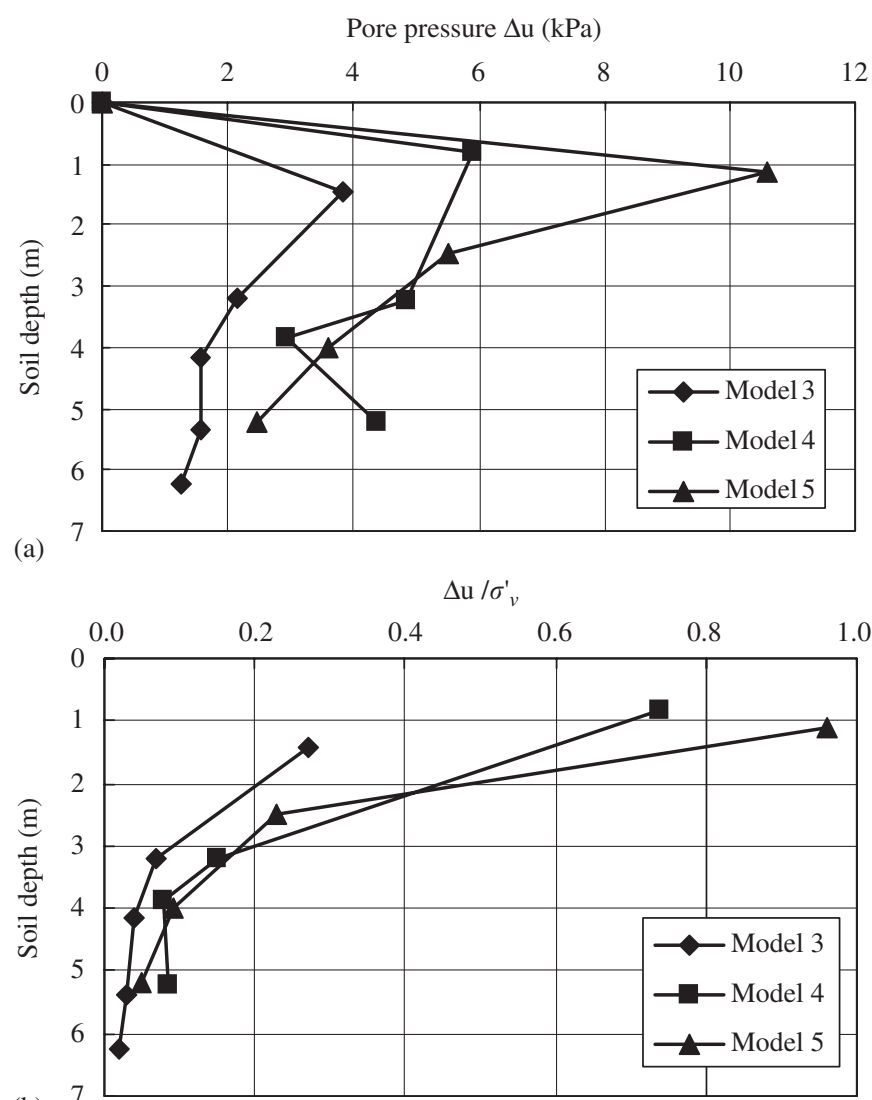

(b)

Fig. 11. Comparison of dynamic responses of Models 3-5.
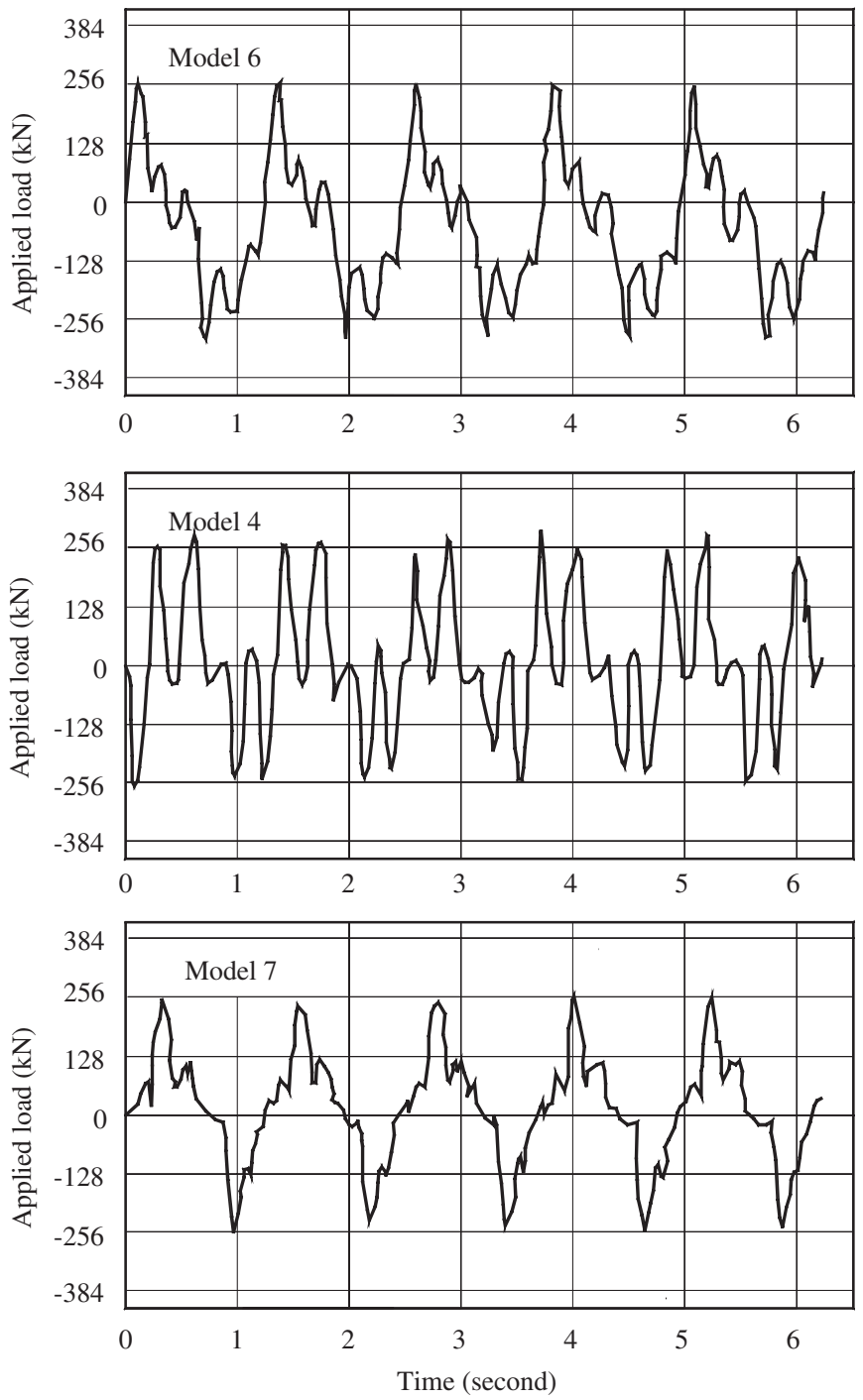

Fig. 13. Applied loading histories of Models 6, 4, and 7.
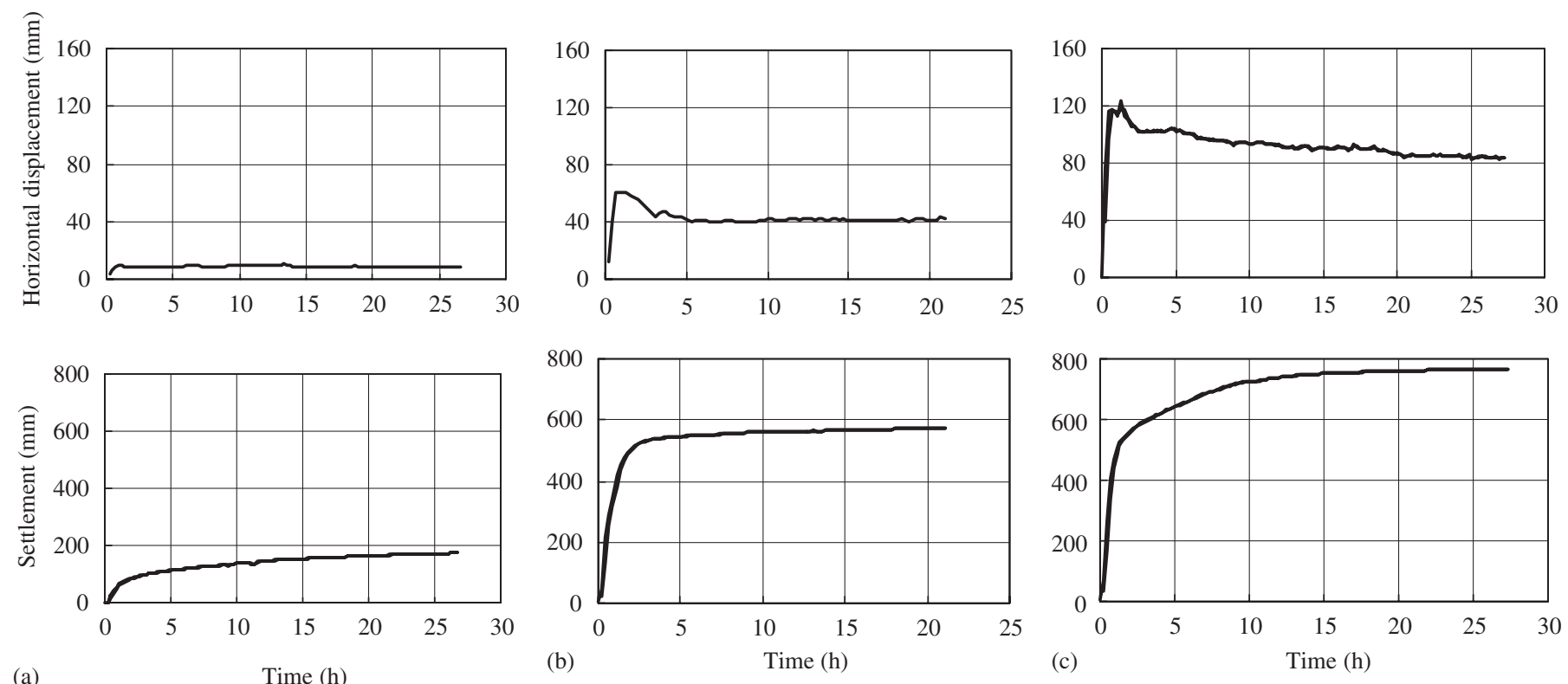

Fig. 12. Horizontal displacements and settlements of Models 3-5. 

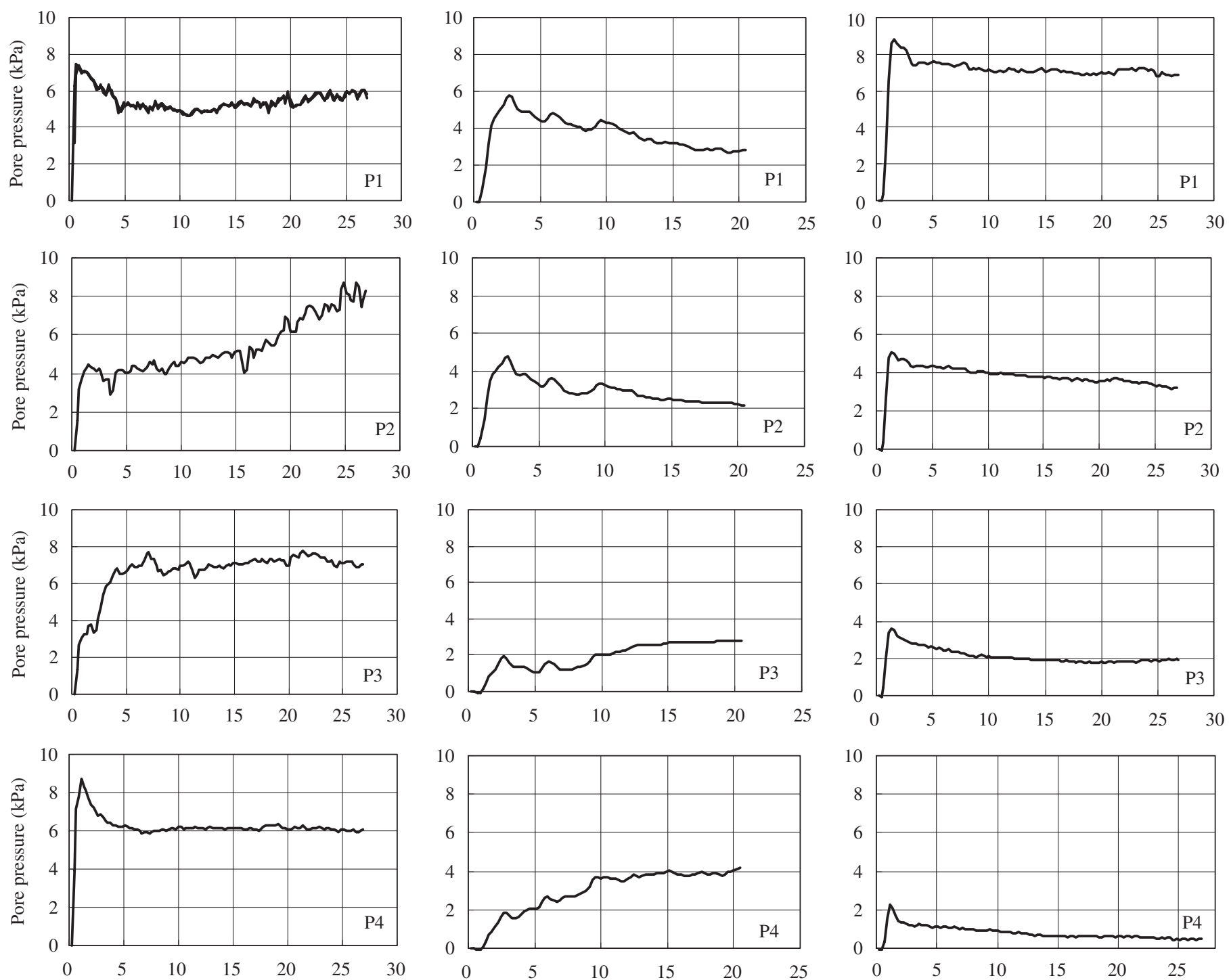

(a)

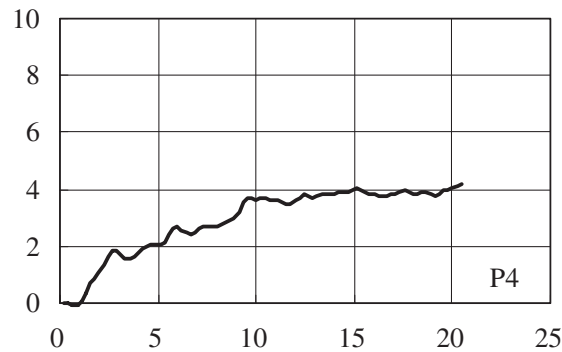

(b)

Time (hour)

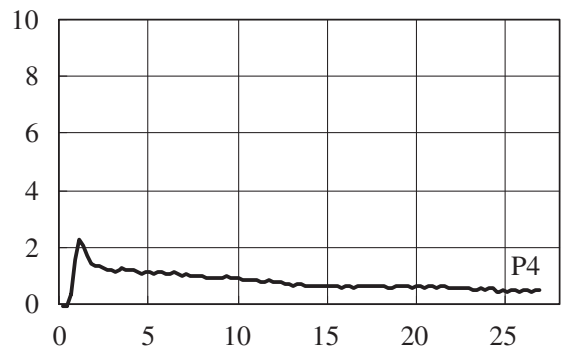

(c)

Time (hour)

Fig. 14. Pore pressure changes in Models 6, 4, and 7.

pressure. Interestingly, the profiles of $\Delta u / \sigma_{\mathrm{v}}^{\prime}$ as shown in Fig. $11 \mathrm{~b}$ are similar for the three models with different aspect ratios. However, the $\Delta u / \sigma_{\mathrm{v}}^{\prime}$ values at about $1.5 \mathrm{~m}$ are different, indicating the effect of the geometry of the bucket. It is shown that the $\Delta u / \sigma_{\mathrm{v}}^{\prime}$ values at P1 for Models 6,4 , and 7 are $0.97,0.74$, and 0.68 , respectively. Consequently, the soil around a bucket foundation with a low aspect ratio is more susceptible to liquefaction.

Fig. 16 shows the lateral and vertical displacements of the bucket foundations in Models 6, 4, and 7. The permanent displacements are reversely correlated to the aspect ratio; namely, the greatest displacement is associated with the smallest aspect ratio. The permanent lateral displacements are 160,40 , and $20 \mathrm{~mm}$, and the permanent vertical displacements are 721,574 , and $257 \mathrm{~mm}$ for the models with aspect ratios of $0.8,1.2$, and 1.5 , respectively.

Figs. 14-16 illustrate how the geometry affects the dynamic response of the foundation. By increasing the aspect ratio, the pore pressure at $\mathrm{P} 1$ at a shallow depth is greatly reduced, thus alleviating the potential of liquefaction in the early period of the cyclic loading. Nevertheless, the $\Delta u / \sigma_{\mathrm{v}}^{\prime}$ profiles are very similar regardless of the aspect ratio. During the long period of excitation, soil softening occurred and induced horizontal displacements and settlements. However, the use of larger embedment depths (i.e., larger aspect ratios) can increase the capacity and decrease the permanent displacements of the foundation caused by long-term excitations.

\section{Conclusions}

Seven centrifuge model tests were performed to study the behavior of suction bucket foundations of a tension leg platform in the Bohai Bay oil field, China. The behavior of the suction bucket foundations under lateral static load 
and long-duration, ice-sheet-induced lateral cyclic loads were investigated.

Under static loading, the load-displacement curves of the buckets $4.8 \mathrm{~m}$ in diameter and $5.76 \mathrm{~m}$ in height are relatively linear at the beginning but exhibit strong
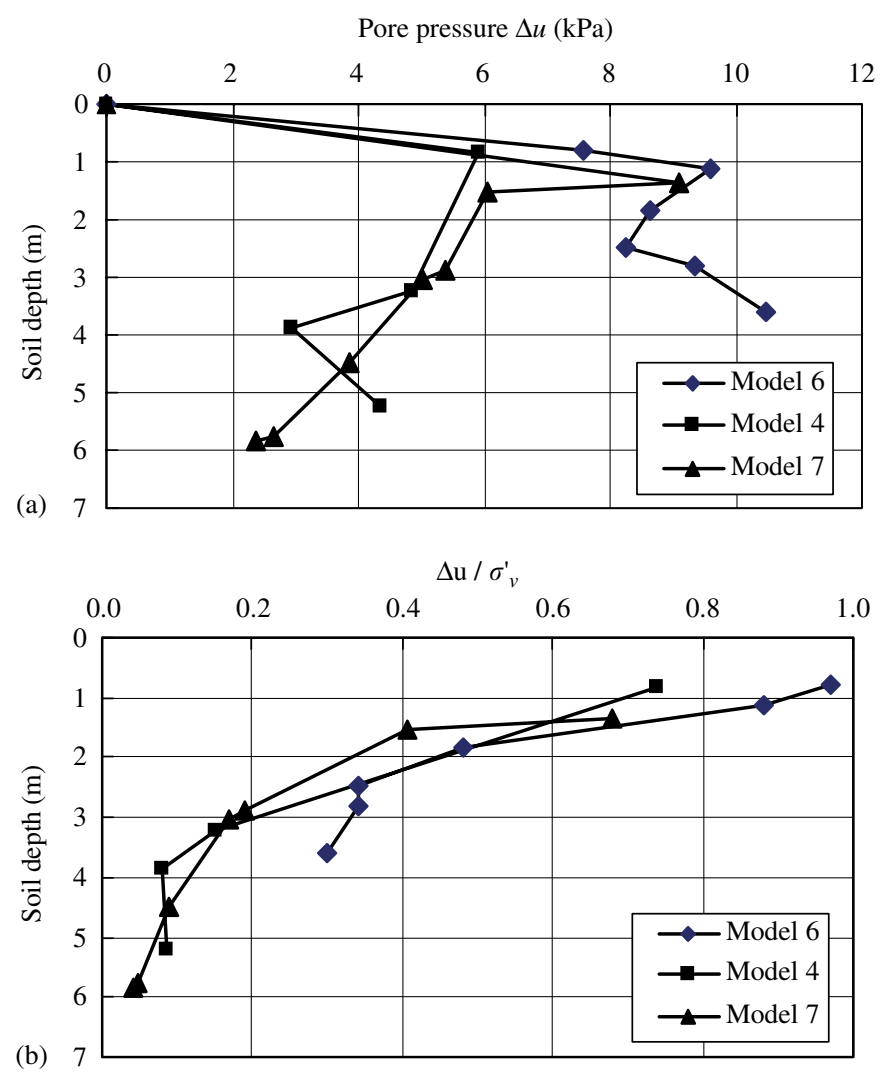

Fig. 15. Comparison of dynamic responses of Models 6, 4, and 7. nonlinearity after a certain load is exceeded. The lateral critical and ultimate capacities of the foundation are found to be 327 and $513 \mathrm{kN}$, respectively.

The results of the dynamic centrifuge tests indicate that strong dynamic responses took place within a depth of $1.0-1.5 \mathrm{~m}$ below the mud line. Liquefaction of the soil at these shallow depths was likely to occur in the first $1-3 \mathrm{~h}$ if the cyclic load intensity was about $70 \%$ of the ultimate static bearing capacity. Significant lateral displacement and settlement of the foundation were induced by long-duration excitations. Therefore, two failure modes might be involved: liquefaction in early excitations and displacement-induced problems after longterm excitations.

The load intensity had a strong effect on the dynamic behavior of the foundation. Under an excitation with intensity close to $1 / 3$ of the static critical capacity, a soil contraction mechanism dominated. The pore pressure built up smoothly before reaching a constant value and liquefaction was unlikely to occur. When the cyclic load was greater, strong soil compaction resulted in a rapid increase of pore-water pressure, which was followed by soil dilation and pore pressure decreasing. For a foundation with a given aspect ratio, increasing the intensity of the cyclic load would increase the liquefaction potential and the permanent displacements of the foundation.

The aspect ratio or the embedment depth has a strong effect on the dynamic response of the suction bucket. By increasing the aspect ratio, the pore pressures were largely reduced, especially at shallow depths, and the soil-softening-induced horizontal displacements and settlements were decreased substantially. However, the distributions of $\Delta u / \sigma_{\mathrm{v}}^{\prime}$ along depth were still similar except at depths $1.0-1.5 \mathrm{~m}$ below the mud line.
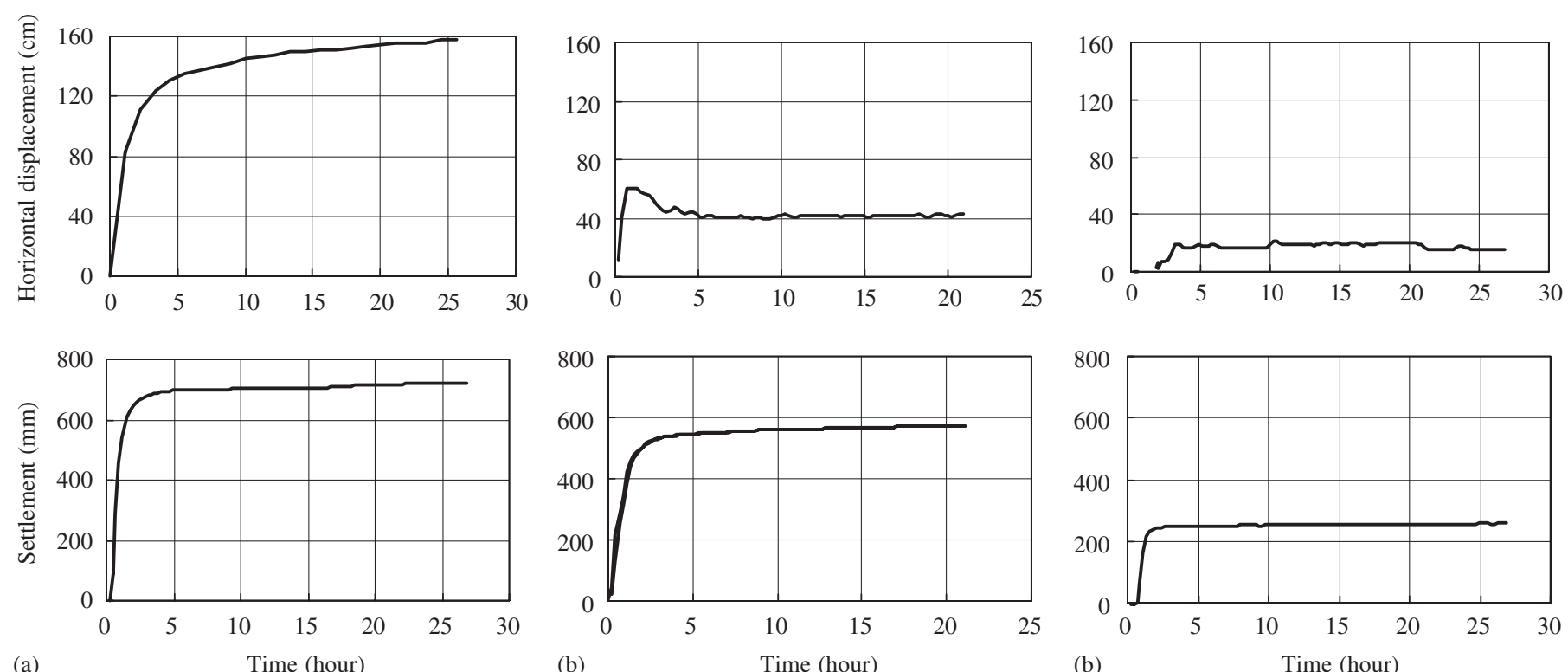

(b)

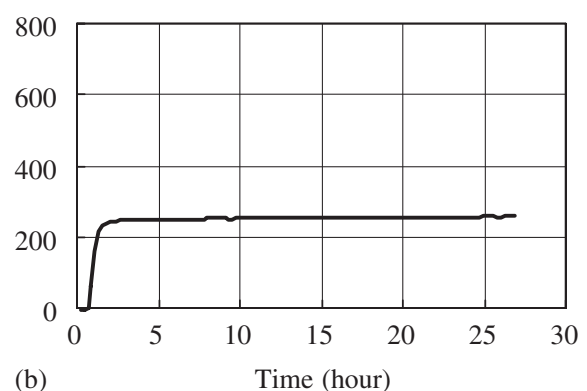

Fig. 16. Horizontal displacement and settlement in bucket foundations in Models 6, 4, and 7. 


\section{Acknowledgements}

The research work was funded by National Natural Science Foundation of China (50679035) and the Tsinghua Basic Research Foundation (Project No. JCxx2005067).

\section{References}

Allersma, H.G.B., Plenevaux, F.J.A., Wintgens, J.F., 1997. Simulation of suction pile installation in sand in a geocentrifuge. Proceedings of the Seventh International Offshore and Polar Engineering Conference, Honolulu, USA, pp. 761-766.

Allersma, H.G.B., Kirstein, A.A.R.B., Brinkgreve, T.S., 1999. Centrifuge and numerical modeling of laterally loaded suction piles. Proceedings of the Ninth International Offshore and Polar Engineering Conference, vol. 1, Brest, France, pp. 711-717.

Bang, S., Cho, Y., 2002. Ultimate lateral loading capacity of suction piles. International Journal of Offshore and Polar Engineering 12 (1), 56-63.

Cao, J.C., 2003. Centrifuge modeling and numerical analysis of the behavior of suction caissons in clay. Ph.D. Thesis, Memorial University of Newfoundland, Canada.

Clukey, E.C., Morrison, M.J., 1993. A centrifuge and analytical study to evaluate suction caissons for TLP application in the Gulf of Mexico. Proceedings of the ASCE Conference on Foundations, Dallas, TX, pp. 141-156.

Clukey, E.C., Morrison, M.J., 1995. The response of suction caissons in normally consolidated clays to cyclic TLP loading conditions. Proceedings of the Offshore Technology Conference, Houston, Texas, pp. 909-915.

Fuglsang, L.D., Steensen-Bach, J.O., 1991. Breakout resistance of suction piles in clay. In: Ko, H.Y., Mclean, F.G. (Eds.), Proceedings of the International Conference on Centrifuge, Boulder, Colorado, pp. 153-159.

Kim, Y.S., Kim, K.O., Cho, Y., Bang, S., Jones, K., 2005. Centrifuge model tests on embedded suction anchors. Proceedings of the 15 th International Offshore and Polar Engineering Conference and Exhibition, Seoul, Korea, pp. 431-435.

Kutter, B.L., James, R.G., 1989. Dynamic centrifuge model tests on clay embankments. Geotechnique 39 (1), 91-106.

Lee, F.H., Scholfield, A.N., 1988. Centrifuge modeling of sand embankments and islands in earthquake. Geotechnique 38 (1), 45-58.
Li, X.S., 2002. A sand model with state-dependent dilatancy. Geotechnique 52 (3), 173-186.

McVay, M.C., Zhang, L.M., Molnit, T., Lai, P., 1998. Centrifuge testing of large laterally loaded pile groups in sands. Journal of Geotechnical and Geoenvironmental Engineering 124 (10), 1016-1026.

Prakasha, K.S., Joer, H.A., Randolph, M.F., 2005. Establishing a model testing capability for deep water foundation systems. In: Gourvenec and Cassidy (Eds.), Proceedings of the 15th International Offshore and Polar Engineering Conference and Exhibition, Seoul, Korea, pp. 309-315.

Pu, J.L., Liu, F.D., Li, J.K., Li, S.Q., Yin, K.T., Sun, Y.S., Jin, P.F., 1994. Development of medium-size geotechnical centrifuge at Tsinghua University. Proceedings of the International Conference on Centrifuge, Singapore, pp. 53-56.

Raines, R.D., Garnier, J., 2004. Physical modeling of suction piles in clay. Proceedings of the International Conference on Offshore Mechanics and Arctic Engineering-OMAE, pp. 621-631.

Renzi, R., Maggioni, W., Smith, F., 1991. A centrifugal study on the behavior of suction piles. In: Ko, H.Y., Mclean, F.G. (Eds.), Proceedings of the International Conference on Centrifuge, Boulder, Colorado, pp. 169-176.

Rowe, P.W., Craig, W.H., Procter, D.C., 1978. Dynamic loaded centrifugal model foundations. Bell Laboratories Record 2, 359-364.

Waston, P.G., Randolph, M.F., 1997. Vertical capacity of caisson foundations in calcareous sediments. Proceedings of the Seventh International Offshore and Polar Engineering Conference, Honolulu, USA, PP. 784-790.

Zhang, L.M., McVay, M.C., Lai, P.W., 1999. Centrifuge modeling of laterally loaded single battered piles in sands. Canadian Geotechnical Journal 36 (6), 1074-1084.

Zhang, L.M., McVay, M.C., Han, S.J., Lai, P.W., Gardner, R., 2002. Effects of dead loads on the lateral response of battered pile groups. Canadian Geotechnical Journal 39 (3), 561-575.

Zhang, J.H., Yan, D., Sun, G.L., Li, W.X., 2003. Development of a dynamic loading device for suction pile in centrifuge. Proceedings of the BGA International Conference on Foundations: Innovations, Observations, Design and Practice, University of Dundee, Scotland, pp. 985-990.

Zhang, J.H., Su, C.M., Sun, G.L., Lu, X.B., 2005. Centrifuge modeling of suction bucket foundation under horizontal dynamic loading. Proceedings of the Sino-Japanese Symposium on Geotechnical Engineering, Shanghai, China, pp. 604-608. 